\title{
Monoolein-based nanocarriers for enhanced folate receptor-mediated RNA delivery to cancer cells
}

\author{
Ivo Lopes ${ }^{1,2}$, Ana C. N. Oliveira ${ }^{1,2}$, Marisa P. Sárria ${ }^{2}$, João P. Neves Silva ${ }^{1}$, Odete Gonçalves ${ }^{1,2}$, Andreia C. Gomes ${ }^{2}$, and \\ Maria Elisabete C. D. Real Oliveira ${ }^{1}$ \\ ${ }^{1}$ Department of Physics, University of Minho, Campus of Gualtar, Braga, Portugal and ${ }^{2}$ Department of Biology, University of Minho, Braga, Portugal
}

\begin{abstract}
We report the development and characterization of a novel nanometric system for specific delivery of therapeutic siRNA for cancer treatment. This vector is based on a binary mixture of the cationic surfactant dioctadecyldimethylammonium chloride (DODAC) and the helper lipid monoolein (MO). These liposomes were previously validated by our research group as promising non-viral vectors for nucleic acid delivery. In this work, the DODAC:MO vesicles were for the first time functionalized with polyethylene glycol and PEG-folate conjugates to achieve both maximal stability in biological fluids and increase selectivity toward folate receptor $\alpha$ expressing cells. The produced DODAC:MO:PEG liposomes were highly effective in RNA complexation (close to 100\%), and the resulting lipoplexes also demonstrated high stability in conditions simulating their administration by intravenous injection (physiological $\mathrm{pH}$, high $\mathrm{NaCl}$, heparin and fetal bovine serum concentrations). In addition, cell uptake of the PEG-folatecoated lipoplexes was significantly greater in folate receptor $\alpha$ positive breast cancer cells (39\% for $25 \mu \mathrm{g} / \mathrm{mL}$ of lipid and $31 \%$ for $40 \mu \mathrm{g} / \mathrm{mL}$ ) when compared with folate receptor $\alpha$ negative cells ( $31 \%$ for $25 \mu \mathrm{g} / \mathrm{mL}$ of lipid and $23 \%$ for $40 \mu \mathrm{g} / \mathrm{mL}$ ) and to systems without PEG-folate ( $\approx 13 \%$ to $16 \%$ for all tested conditions), supporting their selectivity towards the receptor. Overall, the results support these systems as appealing vectors for selective delivery of siRNA to cancer cells by folate receptor $\alpha$-mediated internalization, aiming at future therapeutic applications of interest.
\end{abstract}

\author{
Keywords \\ Cationic liposomes, folate receptor, \\ nanotechnology, PEGylation, targeting
}

\section{History}

Received 5 May 2015

Revised 16 July 2015

Accepted 22 July 2015

Published online 17 August 2015

\section{Introduction}

The discovery of RNA interference (RNAi) (Fire, 2007; Napoli et al., 1990) renewed the appeal for gene therapy. RNAi allows the down-regulation of expression of diseasecausing proteins, thus small interfering RNA (siRNA) molecules pose great interest to load therapeutic vehicles.

The well-established association between the overexpression of one or more genes, and the emergence of multiple atypical phenotypes (e.g. cancer, infection and inflammation, respiratory, neurological and autoimmune disorders) (Schroeder et al., 2010), is the basis for the interest on the therapeutic potential of RNA-induced gene silencing. Additionally, the easiness of siRNA production and its customization further increases the call for its clinical application (Tan et al., 2011).

Therapeutic use of siRNA requires the development of carriers that must: (i) protect siRNA from RNAse degradation; (ii) deliver siRNA to the target cells; (iii) facilitate cellular uptake and endosomal escape and (iv) release siRNA

Address for correspondence: Maria Elisabete C. D. Real Oliveira, Department of Physics, University of Minho, Campus of Gualtar, Braga, Portugal. E-mail: beta@fisica.uminho.pt intracellularly so that it will become accessible to the cellular machinery (Schroeder et al., 2010).

Cationic liposomes are among the most popular carriers for nucleic acids (Ozpolat et al., 2010) as they spontaneously form stable complexes with RNA or DNA through electrostatic interactions (Wolff \& Rozema, 2008), providing an efficient way to deliver the genetic cargo inside the cells (Tros de Ilarduya et al., 2010). Although lipoplexes produced with solely cationic lipids may exhibit good transfection efficiency, the inclusion of helper neutral lipids, such as dioleoylphosphatidylethanolamine (DOPE), cholesterol (Chol) (Dabkowska et al., 2012) and monoolein (MO) (Oliveira et al., 2014; Silva et al., 2011, 2014a,b), can improve stability in physiological conditions and enhance endosome release of therapeutic RNA or DNA. Unique properties of MO, such as a tendency to form inverted non-lamellar structures and the ability to increase lipid bilayer fluidity may, therefore, enhance the delivery of the carried payload into the cytosol of the cells (Oliveira et al., 2014; Silva et al., 2011, 2014a,b).

Adequate interaction with biological fluids is crucial for effective target site delivery, particularly for systemic applications. The potential of cationic liposomes as vehicles for therapeutic molecules may be hampered by their interaction with serum proteins, lipoproteins and the extracellular matrix, 
making them prone to undesired aggregation and/or nucleic acid release before reaching the target cells (Ozpolat et al., 2010). Additionally, lipoplexes are also susceptible of activating the immunological complement system, leading to rapid clearance by macrophages of the reticuloendothelial system, and induce strong toxicity (Dokka et al., 2000; Lv et al., 2006). siRNA delivery systems must thus be formulated in such a way that the carrier may provide a hydrated steric barrier around the complex, minimizing its associated toxicity. This can be achieved by using materials such as polyethylene glycol (PEG) in the lipoplex formulation, resulting in longer circulation half-times (Andresen et al., 2005; Gabizon et al., 2003), exploiting the enhanced permeability and retention (EPR) effect of the tumor-associated endothelium (Andresen et al., 2005; Maeda, 2001), and also reducing lipoplex-associated toxicity (Filion \& Phillips, 1997). Additionally, liposome functionalization with ligands to a specific cancer cell marker will allow a targeted delivery to tumor cells, increasing delivery to specific sites and therefore reducing nonspecific toxicity in healthy tissues (Immordino et al., 2006).

Several cancer cell markers, such as the folate receptor $\alpha$ $(\mathrm{FR} \alpha)($ a highly selective tumor marker that is overexpressed in several epithelial cancers, including breast cancer) (Kalli et al., 2008), the transferrin receptor, and the vitronectin receptor, have been commonly used as targets for specific drug delivery. This has been accomplished by functionalization with high affinity ligands such as folate, antibodies, antibody parts (Fab) and RGD (Arg-Gly-Asp) peptides (Ozpolat et al., 2010).

Taking advantage of the physico-chemical properties of PEGylated cationic liposomes to benefit from the EPR effect, and considering the well-recognized potential as therapeutic carriers of siRNA molecules, we aimed to produce stable long circulating lipoplexes based on cationic liposomes DODAC:MO:PEG:PEG-Folate for folate-mediated delivery of therapeutic siRNA molecules to $\mathrm{FR} \alpha$ positive $\left(\mathrm{FR} \alpha^{+}\right)$ cancer cells.

\section{Materials and methods}

\section{Materials}

The cationic surfactant dioctadecyldimethylammonium chloride (DODAC) was purchased from Tokyo Kasei (Tokyo, Japan), and the neutral tensioactives 1,2-distearoyl-sn-glycero-3-phosphoethanolamine- $\mathrm{N}$-[methoxy(polyethylene glycol)-2000] ammonium salt (PEG(2000)-PE) and 1,2distearoyl-sn-glycero-3-phosphoethanolamine- $\mathrm{N}$-[folate(polyethylene glycol)-2000] ammonium salt (PEG(2000)-PEFolate) from Avanti Polar Lipids (Alabaster, AL). The helper 1-monooleoyl-rac-glycerol (St. Louis, MO), heparin from the porcine intestinal mucosa, Dulbecco's Modified Eagle's medium (DME medium), antibiotic/mycotic solution, sodium chloride $(\mathrm{NaCl})$, Trizma ${ }^{\circledR}$ base, Thiazoyl Blue Tetrazolium Bromide (MTT), chloroform, methanol, and RNA from Torula sp. yeast were obtained from SigmaAldrich (St Louis, MO). The RiboGreen kit with TE buffer RNase free $(20 \times)$, the fluorescent lipid probe Lissamine Rhodamine B 1,2-dihexadecanoyl-sn-glycero-3-phosphoethanolamine Triethylammonium salt (Rhodamine B DHPE) and heat-inactivated fetal bovine serum (FBS) were acquired from Invitrogen (Eugene, OR). Potassium dihydrogen phosphate $\left(\mathrm{KH}_{2} \mathrm{PO}_{4} \bullet 3 \mathrm{H}_{2} \mathrm{O}\right)$ was purchased from Panreac (Barcelona, Spain), dipotassium hydrogen phosphate trihydrate $\left(\mathrm{K}_{2} \mathrm{HPO}_{4}\right)$, and ethanol absolute from Merck (Darmstadt, Germany), and RNase Zap from Ambion (Eugene, USA); L-929, MDA-MB-468 and MDA-MB-435 from the American Type Culture Collection (ATCC) bank. Hanks' balanced salt solution (HBSS) was obtained from Lonza (Verviers, Belgium).

\section{Preparation of liposomes and RNA lipoplexes}

Appropriated volumes of the lipid stock solutions (DODAC, MO, PEG(2000)-PE (PEG) and PEG(2000)-PE-Folate (PEGFol) in ethanol) were mixed in a round bottom flask in order to obtain the desired lipid molar ratios: DODAC:MO (2:1) (hereafter referred as DODAC:MO); DODAC:MO:PEG 1\%, $2 \%$ or $5 \%$ PEG) (hereafter referred as DODAC:MO:PEG) and DODAC:MO: 4\% PEG 1\% PEG-Fol (hereafter referred as DODAC:MO:PEG-Fol). Ethanol was evaporated in a rotatory evaporator VV Micro Rotary Evaporator (Heidolph) $\left(30^{\circ} \mathrm{C}\right.$, $10 \mathrm{~min}$ ), forming a homogeneous lipid film. The lipid film was then hydrated with ultrapure water, during $10 \mathrm{~min}$ at $30^{\circ} \mathrm{C}$, to obtain the desired liposome concentration. In each production, the liposome solution was subjected to 5 extrusion cycles at $55^{\circ} \mathrm{C}$ (one time through a $400 \mathrm{~nm}$ pore-sized filter and subsequently four times through a $100 \mathrm{~nm}$ pore-sized filter (Track-Etched Membranes (Whatman Nuclepore)) in a Lipex Extruder (Northern Lipids), in order to obtain homogeneous unilamellar liposome dispersions.

RNA lipoplexes were prepared by adding a proper volume of liposomes $(0.5 \mathrm{mM})$ to $100 \mu \mathrm{L}$ of RNA solution $(10 \mu \mathrm{g} / \mathrm{mL}$ in phosphate buffer $(20 \mathrm{mM}, 150 \mathrm{mM}$ of $\mathrm{NaCl}, \mathrm{pH} 6,8)$ ), to achieve the desired charge ratios (CR) (ratio between the number of moles of positive charge of the cationic liposomes and the number of moles of negative charge of the nucleic acids). The mixtures were then subjected to strong vortexing, allowed to stabilize for $1 \mathrm{~h}$, and then diluted to a final RNA concentration of $1 \mu \mathrm{g} / \mathrm{mL}$.

\section{Dynamic (DLS) and electrophoretic light scattering (ELS) studies of liposomes and lipoplexes}

DODAC:MO liposomes (mol:mol) were prepared at $1 \mathrm{mM}$ concentration in ultrapure water with different percentages of PEG $(0 \%, 1 \%, 2 \%$ and 5\% (mol\%)), and lipoplexes were prepared, with DODAC:MO and DODAC:MO:PEG liposomes, at CR 0,$5 ; 1 ; 2 ; 4 ; 6 ; 8 ; 10 ; 15 ; 20 ; 25$ and 30 . The hydrodynamic diameter and zeta potential ( $\zeta$-potential) of liposomes and lipoplexes were assessed in a Zetasizer nano ZS (Malvern, Worcestershire, United Kingdom).

\section{RNA complexation dynamics}

DODAC:MO and DODAC:MO:PEG lipoplexes were prepared at CR 0,$5 ; 1 ; 2 ; 4 ; 6 ; 8 ; 10 ; 15$ and 20 , and the RNA complexation dynamics was followed by dynamic and electrophoretic light scattering (ELS) measurements, as described in the Section "Dynamic (DLS) and Electrophoretic light scattering (ELS) studies of liposomes 
and lipoplexes', and by the RiboGreen fluorimetric assay, according to the manufacturer specifications.

Briefly, lipoplexes were incubated with RiboGreen solution in the dark ( $5 \mathrm{~min}$ ) and then the fluorescence was measured in a Fluoroskan ACEN FL Microplate Fluorometer and Luminometer (Thermo Scientific, Waltham, MA), using the excitation/emission filter pair of $485 / 538 \mathrm{~nm}$. A calibration curve was made in order to assure the linearity between the RiboGreen fluorescence and RNA concentration. The percentage of free RNA was attained from a control, of the same quantity of RNA used in the preparation of the lipoplexes.

\section{Stability of lipoplexes}

DODAC:MO:PEG lipoplexes were prepared at CR 10 as described and diluted to a final RNA concentration of $1 \mu \mathrm{g} /$ $\mathrm{mL}$ in different solutions mimicking physiological parameters: ultrapure water, saline solutions $([\mathrm{NaCl}] \mathrm{0} / 5 / 10 / 50 / 100 /$ $150 \mathrm{mM}$ ), acidic solutions ( $\mathrm{pH} 3$ and 5), and serum solutions (FBS) of 30 and $80 \% \mathrm{v} / \mathrm{v})$. The hydrodynamic diameter and $\zeta$-potential were assessed in a Zetasizer nano ZS (Malvern, Worcestershire, United Kingdom) immediately after and, in the case of serum stability, also at 3, 6 and $24 \mathrm{~h}$ of incubation, at room temperature.

In order to circumvent the experimental error associated with the mean diameters of very polydisperse suspensions (Polydispersity Index (PDI) values above 0.5), the weighted mean for all populations appearing in the size distributions was determined according to the following equation:

$$
W \cdot M \cdot=\sum\left(\frac{P K_{x} \times P K_{x} \%}{100}\right),
$$

where $P K_{x}$ stands for the populations diameter and $P K_{x} \%$ for their relative percentages.

\section{Destabilization of lipoplexes by heparin}

To monitor the destabilization of lipoplexes by heparin, DODAC:MO:PEG lipoplexes were prepared at CR 10 as described, and diluted to a final RNA concentration of $1 \mu \mathrm{g} / \mathrm{mL}$ by the addition of appropriate volumes of an aqueous solution of the negative polyelectrolyte heparin $(0.121 \mathrm{mM})$, as to reduce the CR from 10 to $5 ; 2.5$ and 0.5 . The final volume was completed with ultrapure water.

The lipoplexes/heparin solutions were subjected to vortex and the RNA concentration was determined following the RiboGreen protocol previously described. An additional blank, consisting of a mixture of $100 \mu \mathrm{L}$ of heparin with the same concentration used to obtain the CR 0 .

\section{Cellular assays}

Cytotoxicity of liposomes and lipoplexes

L-929 cell line (fibroblasts of subcutaneous connective tissue of Mus musculus (mouse)) was used in this study to access the cytotoxicity of the liposomes. This cell line, as well as the human cell line MDA-MB-468 (epithelial adenocarcinoma cells of the mammary gland of Homo sapiens, known to express FR $\alpha$ ) was used in the cytotoxicity assays of lipoplexes. The cell lines were cultured in DME medium, supplemented with $10 \%(\mathrm{v} / \mathrm{v})$ heated inactivated FBS and $1 \%(\mathrm{v} / \mathrm{v})$ antibiotic/ antimycotic solution, in an atmosphere of $5 \% \mathrm{CO}_{2}$ and $37^{\circ} \mathrm{C}$. After the growth exponential phase was achieved, L-929 and MDA-MB-468 cells were plated at a density of 60000 and 83400 cells $/ \mathrm{mL}$, respectively, and incubated overnight at $5 \%$ $\mathrm{CO}_{2}$ and $37^{\circ} \mathrm{C}$ for cellular adhesion.

The cells where then incubated with the following conditions: DODAC:MO liposomes with $0 \%, 1 \%, 2 \%$ and $5 \%$ of PEG, diluted in DME medium at the concentrations of 5,25 and $100 \mu \mathrm{g} / \mathrm{mL}$. A cell viability control (fresh DME medium), and a cell death control (30\% (v/v) DMSO) were further added to the experimental set. Lipoplexes were prepared as described above, diluted in DME medium to obtain 5, 25 and $100 \mu \mathrm{g} / \mathrm{mL}$, and incubated using the same procedure as for the liposomes. An additional control with RNA was also used.

After a 48 and 72-h incubation period in $5 \% \mathrm{CO}_{2}$ and $37{ }^{\circ} \mathrm{C}$, the cytotoxicity was assessed by the MTT assay. Briefly, the cell medium was aspirated, $500 \mu \mathrm{L}$ of a MTT $(1 \times)$ (stock solution of $5 \mathrm{mg} / \mathrm{mL}$ ) in DME medium was added to each well, and the cells were incubated for $2 \mathrm{~h}$ at $37^{\circ} \mathrm{C}, 5 \% \mathrm{CO}_{2}$ for the formation of the formazan crystals. The supernatant medium was then carefully aspirated and $500 \mu \mathrm{L}$ of a DMSO/Ethanol [1:1 (v/v)] solution was added to each well to dissolve the crystals. Finally, the absorbance was read at $570 \mathrm{~nm}$ in a SpectraMax Plus 384 absorbance Plate Reader (Molecular Devices, Sunnyvale, CA), using the appropriated software (SOFT Max Pro, Sunnyvale, CA) protocol.

\section{Cellular uptake of liposomes and lipoplexes}

DODAC:MO:PEG and DODAC:MO:PEG-Fol liposomes, labeled with the fluorescent probe Rhodamine B DHPE, were prepared by incorporating the fluorochrome at a ratio of 1:200 (mol probe: mol lipid) into the lipid film prior to hydration.

MDA-MB-468 $\left(\mathrm{FR} \alpha^{+}\right)$and MDA-MB-435 (Melanoma of Homo sapiens, folate receptor $\alpha$ negative cells $\left.\left(\mathrm{FR} \alpha^{-}\right)\right)$were used for cellular uptake assays. The cells were cultured in DME medium supplemented with $10 \%(\mathrm{v} / \mathrm{v})$ heated inactivated $\mathrm{FBS}$ and $1 \%(\mathrm{v} / \mathrm{v})$ antibiotic/antimycotic solution (5\% $\mathrm{CO}_{2}, 37^{\circ} \mathrm{C}$ ). After reaching the exponential phase of growth, both cell lines were plated at 83400 and 55600 cells $/ \mathrm{mL}$, respectively.

DODAC:MO:PEG and DODAC:MO:PEG-Fol lipoplexes were prepared as previously described for the cytotoxicity assays, diluted to $40 \mu \mathrm{g} / \mathrm{mL}$ in HBSS folate free medium, and added to the cells. A control with HBSS was additionally considered. After a 6-h incubation period, the extracellular medium was removed and the cells were washed with PBS to remove any extracellular fluorescence traces. After washing, the cells were lysed with $500 \mu \mathrm{L}$ Tris buffer $(10 \mathrm{mM})$ and transferred to eppendorfs. $450 \mu \mathrm{L}$ of each lysate were immediately diluted to a final volume of $2000 \mu \mathrm{L}$, with the same Tris buffer, and the fluorescence was measured in a Jobin Yvon Fluorolog-3 (Horiba, Kyoto, Japan) spectrofluorimeter using excitation wavelength set to $560 \mathrm{~nm}$ and collecting the emission spectrum between 570 and $700 \mathrm{~nm}$. A blank was prepared with Tris buffer and measured in the same conditions.

The lipoplexes concentration on the cell lysates was inferred from calibration curves of the fluorescence emission 
spectrum area versus the concentration of the liposomes (since they had better coefficients of determination $\left(R^{2}\right)$ when compared with those of the lipoplexes).

\section{Statistical analysis}

Assumptions were met prior to data analysis. All data were tested for normality (the Kolmogorov-Smirnov test) and homogeneity of variance (Levene's test). In cases of heteroscedasticity, data were square root-transformed before parametric analysis.

To investigate the influence of DODAC:MO liposomes on metabolic toxicity (Figure 1C and D), a two-level nested design analysis of variance (ANOVA) was conducted: lipid concentration and PEG percentage. Different time-exposure effects were analyzed separately.

An ANOVA model (two factors: $\mathrm{NaCl}$ concentration and type of formulation) was conducted to identify parameters affecting stability in conditions relevant to systemic administration, using mean size as the dependent variable.

In order to evaluate the metabolic cytotoxicity induced by DODAC:MO:PEG lipoplexes on different cell lines (Figure 4), a two-level nested design ANOVA was conducted: lipoplexes concentration: RNA control; cell line. Different time-exposure effects were analyzed separately.

The effect of folate functionalization on lipoplexes on cellular uptake (Figure 5) was investigated recurring to a three-level nested design ANOVA: cell line; presence or absence of folate and lipoplexes concentration.

Non-parametric tests were applied when appropriated, namely chi-square tests: (i) using the total average of each variable (size, PDI and $\zeta$-potential) as the expected value. The statistical analysis was conducted where the observed values derived from the average values obtained in the control (no PEG) and in the different percentages of PEG (Figure 1), at different $\mathrm{CR}$, for DODAC:MO and DODAC:MO:PEG lipoplexes (Figure 2A-D), and at different $\mathrm{pH}$ environments, either for liposomes or lipoplexes (Figure 3C and D). Using the total average of RNA-free percentages (independently of PEG presence) as the expected value, a chi-square test was conducted where the observed values derived from the average values obtained at different CR (Figure 2E).

Post hoc comparisons were conducted using StudentNewman-Keuls (SNK). A $p$ value of 0.05 was used for significance testing. Analyses were performed in STATISTICA (StatSoft v.7, Tulsa, OK).

\section{Results}

\section{Optimization of the percentage of PEG in the liposomal formulation}

DODAC:MO and DODAC:MO:PEG liposomes were prepared by the lipid film hydration method, followed by extrusion. The flexibility of the PEG polymer allows for a
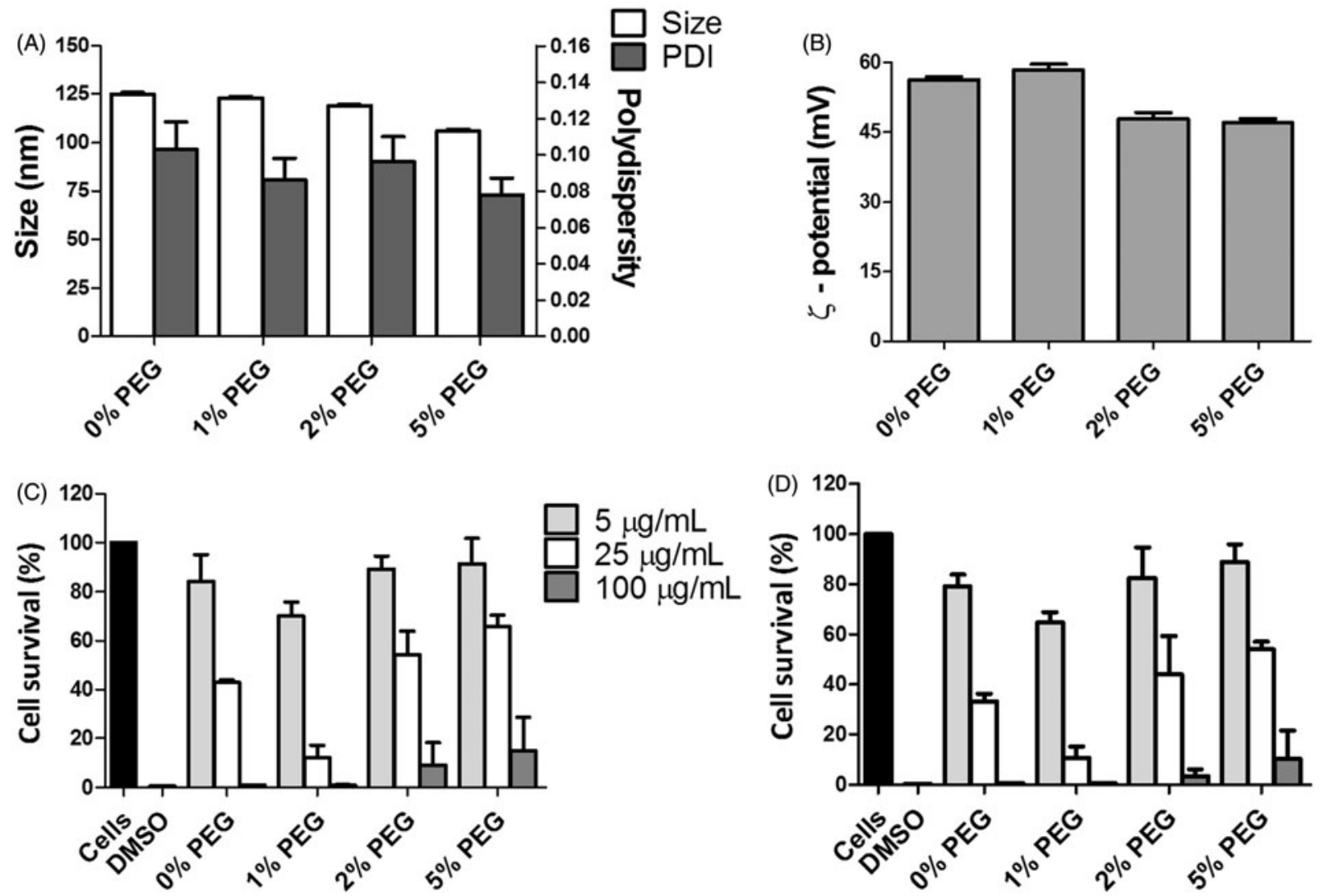

Figure 1. Optimization of the PEG percentage on the liposome formulation. Size (nm) and PDI (A) and $\zeta$-potential (mV) (B) of liposomes DODAC:MO with increasing quantities of PEG $(0 \%, 1 \%, 2 \%$ and $5 \%$ mol:mol). In vitro evaluation of the metabolic cytotoxicity induced by DODAC:MO liposomes on L-929 cell line after $48 \mathrm{~h}(\mathrm{C})$ and $72 \mathrm{~h}(\mathrm{D})$ of incubation. DODAC:MO liposomes with different PEG percentages ( $0 \%, 1 \%$, $2 \%$ and $5 \%$ ) were incubated (at 5, 25 and $100 \mu \mathrm{g} / \mathrm{mL}$ lipid concentration) with the cells, and the viability was determined by the MTT assay. Cell culture medium and 30\% (v:v) DMSO were used as controls. 
relative small number of molecules to provide a protective coating (Torchilin, 2005). Therefore, we have chosen to prepare our liposomes with $0 \%, 1 \%, 2 \%$ or $5 \%$ of PEG. The average mean size, PDI values and $\zeta$-potential of the liposomes prepared with different percentages of PEG are shown in Figure 1(A) and (B).

All produced liposomes had a small hydrodynamic diameter $(<125 \mathrm{~nm})$ with PDI values $<0.1$ (Figure 1A). The size of liposomes decreases when the percentage of PEG is increased, although no statistical differences were found among groups $(\chi 2=1.820 ; \mathrm{DF}=3 ; p=0.610604)$. The same trend is observed for the PDI $\left(\chi^{2}=0.004\right.$; $\mathrm{DF}=3 ; p=0.999933)$ and the surface charge $\left(\chi^{2}=1.920\right.$ $\mathrm{DF}=3 ; p=0.589128)$ of liposomes: the higher the percentage of PEG, the lower the PDI (Figure 1A) and the $\zeta$-potential (Figure 1B). Nevertheless, for the highest percentage of PEG used (5\%), the $\zeta$-potential was still higher than $+40 \mathrm{mV}$.

A cytotoxicity assay was subsequently performed in order to evaluate the effect of PEG on cellular viability, to choose the most biocompatible formulation for further functionalization. The MTT assay was used to evaluate the cytotoxicity of DODAC:MO liposomes with different percentages of PEG $(0 \%, 1 \%, 2 \%$ and $5 \%)$ on L-929 cells (Figure 1 bottom), a cell line routinely used for validation of biomaterials' biocompatibility. Higher liposome concentration induced increasing metabolic toxicity in L-929 cells, both after 48 and $72 \mathrm{~h}$ of incubation, for all the formulations tested $(F(18,70)=7.318$, $p<0.01$, nested ANOVA). However, the presence of PEG boosts cytocompatibility, as observed by higher percentages

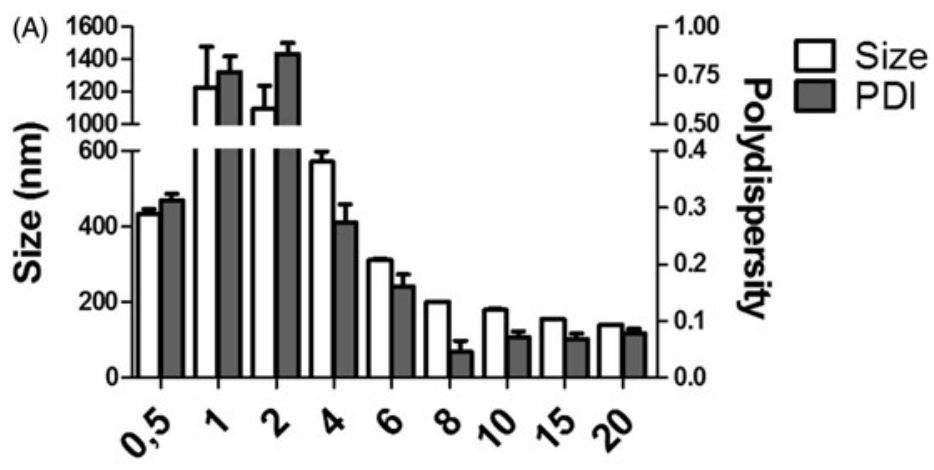

C. $\mathbf{R}$.

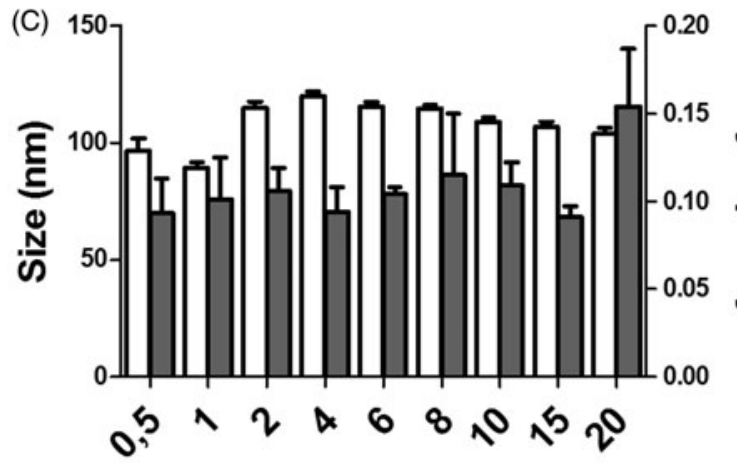

C. $\mathbf{R}$.

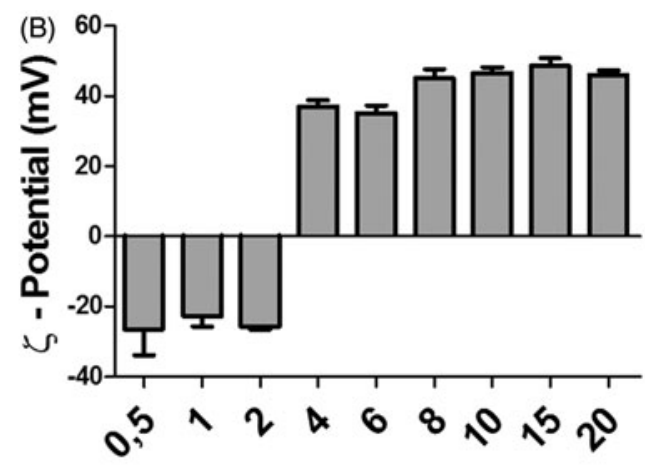

C. $\mathbf{R}$.

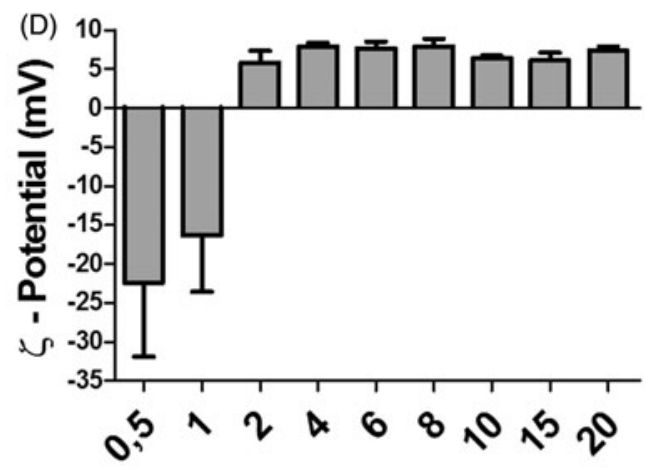

C. R.

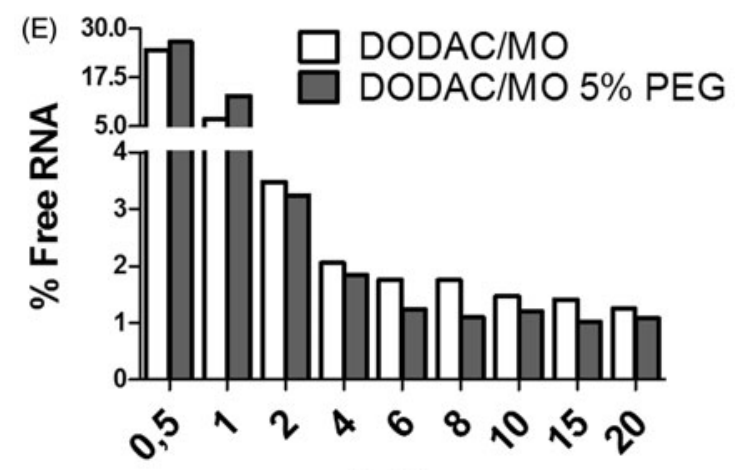

C. R.

Figure 2. RNA complexation dynamics by DODAC:MO and DODAC:MO:PEG liposomes. Lipoplexes were prepared, at increasing CR, with DODAC:MO (A and B) and DODAC:MO:PEG liposomes (C and D). Size (nm), PDI values (A and C) and $\zeta$-potential (mV) (B and D) are shown. Additionally, the percentage of free RNA after addition of DODAC:MO and DODAC:MO:PEG liposomes to a RNA solution, forming lipoplexes at different CR, was evaluated with the RNA intercalating probe Ribogreen (E). 
of cell survival obtained after incubation with DODAC:MO liposomes with 2\% and 5\% PEG. Accordingly, the percentage of PEG chosen to form lipoplexes was 5\%, due to the lower toxicity associated with DODAC:MO:PEG liposomes.

\section{RNA incorporation in DODAC:MO and DODAC:MO:PEG liposomes}

DODAC:MO and DODAC:MO:PEG lipoplexes were prepared at different CR and the RNA complexation was followed by dynamic and ELS measurements (Figure 2A-D), as well as by the RiboGreen fluorimetric assay (Figure 2E).

Figure 2(A) shows very high mean sizes (from 400 to $1250 \mathrm{~nm})$ and PDI values (0.3-0.9) for DODAC:MO lipoplexes prepared at low CR ( 0.5 up to CR 4). Above these CRs a reduction in both parameters is observed. A negative $\zeta$-potential $(-20 \mathrm{mV})$ of the lipoplexes is observed below CR 4 , that becomes positive at higher CRs. The $\zeta$-potential of lipoplexes stabilizes around $+50 \mathrm{mV}$ (Figure 2B).

The inclusion of PEG in the liposomal formulation alters RNA complexation dynamics (Figure 2C and D), since at low CR (0.5 up to 4$)$ the expressive increase in the lipoplexes size observed for DODAC:MO lipoplexes $\left(\chi^{2}=2855.361\right.$; $\mathrm{DF}=8 ; p<0.01)$ is no longer detected $\left(\chi^{2}=7.341 ; \mathrm{DF}=8\right.$; $p=0.500290$ ), and the mean size only varies between 90 and $125 \mathrm{~nm}$ for all the C.R tested. Regarding the $\zeta$-potential, the change from negative to positive occurs at lower CR (CR 2 instead of CR 4). Nevertheless, DODAC:MO:PEG is less positively charged (around $+7 \mathrm{mV}$ ) when compared with DODAC:MO lipoplexes (Figure 2D). Interestingly, no significant variation in $\zeta$-potential for $\mathrm{CR}>4$ occurs, independently of the inclusion of PEG in the liposomal formulation (no PEGylated-liposomes: $\chi^{2}=3.548 ; \quad \mathrm{DF}=5 ; \quad p=0.616160$; PEGylated-liposomes: $\left.\chi^{2}=0.442 ; \mathrm{DF}=5 ; p=0.994104\right)$.

The RNA complexation process was also evaluated by the RiboGreen assay (Figure 2E). RiboGreen is a RNA fluorescent intercalating probe that is used to quantify RNA in solution. When RNA is encapsulated inside the liposomes, the probe is excluded to the surrounding aqueous environment where its fluorescence quantum yield is markedly reduced. Figure 2(E) shows the percentage of free RNA of the different $\mathrm{CR}$ prepared with DODAC:MO and DODAC:MO:PEG liposomes.

For both types of liposomes (with and without PEG), the fluorescence intensity significantly decreases as the CR increases $\left(\chi^{2}=92.056 ; \mathrm{DF}=8 ; p<0.01\right.$ and $\chi^{2}=109.716$; $\mathrm{DF}=8 ; p<0.01$, respectively) (Figure 2E). For CR 0.5 and 1 , a clear difference between DODAC:MO and DODAC:MO:PEG is observed, with higher percentage of free RNA when PEG is present in the formulation, a trend that is inverted from CR 2. After CR 6 both DODAC:MO and DODAC:MO:PEG liposomes reach their maximum RNA complexation ability.

\section{Stability of DODAC:MO:PEG lipoplexes in physiological mimicking conditions}

Different aspects of the blood circulation conditions, such as salt and the presence of serum proteins, were mimicked in vitro in order to evaluate the stability of DODAC:MO:PEG lipoplexes. Another factor often reported to destabilize lipoplexes is their interaction with cell surfaces. Therefore, the interaction of lipoplexes with a model proteoglycan was studied, in order to evaluate lipoplex stability upon interaction with cell membranes. Additionally, the behavior of the lipoplexes after cellular internalization was studied by simulating the acidic conditions in endosomes.

Figure 3(A), (B), (E) and (F) shows DODAC:MO:PEG lipoplexes (CR 10) behavior when subjected to the blood mimicking conditions tested: increasing salt concentrations and presence of serum.

The lipoplexes mean diameter remains practically unchanged for all the $\mathrm{NaCl}$ concentrations tested, with very low PDI values associated $(<0.15)$ (Figure 3A). These results are different from the behavior observed for the liposomes (Lopes, 2013), where the increase in $\mathrm{NaCl}$ concentration leads statistical significant decrease in their mean size $(F(5,48)=67.688, p<0.01$, factorial ANOVA $)$.

Figure 3(B) shows a decrease in the $\zeta$-potential of the lipoplexes with increasing $\mathrm{NaCl}$ concentration, as was also observed for the parent liposomes (Lopes, 2013).

Figure 3(E) and (F) shows that lipoplexes present a weighted mean size smaller than the aggregates formed by the serum proteins. Immediately after incubation of lipoplexes in serum (30 - Figure 3E and $80 \%$ - Figure 3F), a decrease in their weighted mean diameter was observed, when compared with their size in water. These results oppose what was observed for the liposomes (Lopes, 2013), whose size increased more than $70 \mathrm{~nm}$, immediately after incubation with serum. This mean size is maintained relatively constant for $6 \mathrm{~h}$ of incubation, and only after $24 \mathrm{~h}$ incubation large aggregates are detectable independently of the percentage of serum tested. Similarly, the size of lipoplexes in either $30 \%$ or $80 \%$ of serum suffered drastic alterations, detectable at $24 \mathrm{~h}$ of incubation (Figure $3 \mathrm{E}$ and $\mathrm{F}$ ).

Another factor often reported as destabilizing lipoplexes is the presence of negatively charged moieties, such as proteoglycans and phosphatidylserine, at the cell and endosome membranes (Obata et al., 2010; Oliveira et al., 2014; Yang et al., 2010), and also the acidic environment of the endosome (Kwon, 2012; Midoux et al., 2009). Heparin, a polysaccharide with a high negative charge density, was used as a model proteoglycan, and a RiboGreen assay was performed to quantify the amount of RNA released from the lipoplexes. Iincubation of DODAC:MO:PEG lipoplexes with heparin led to a release of 37\% (CR 5), 34\% (CR 2.5) and 36\% (CR) of RNA from the complex.

The acidic conditions of endosomes were simulated by adding $\mathrm{H}_{3} \mathrm{O}^{+}$to the lipoplexes, in order to study their behavior after internalization by endocytosis. Figure 3(C) and (D) shows the results of the mean hydrodynamic diameter and $\zeta$-potential of DODAC:MO:PEG lipoplexes incubated in aqueous solutions at different $\mathrm{pHs}$.

As seen in Figure 3(C) and (D), no important effect driven by the $\mathrm{pH}$ was observed on the size $\left(\chi^{2}=0.056\right.$; $\mathrm{DF}=2$; $p=0.972459) \quad$ and $\zeta$-potential $\quad\left(\chi^{2}=0.101 ; \quad \mathrm{DF}=2\right.$; $p=0.950555)$ of the lipoplexes, although an increase in PDI value can be detected at lower pHs, but not statistically significant $\left(\chi^{2}=0.015 ; \mathrm{DF}=2 ; p=0.992532\right)$. This is not true for liposomes, since a slight size decrease $\left(\chi^{2}=0.422\right.$; $\mathrm{DF}=2 ; p=0.809927)$ and a significant $\zeta$-potential reduction 

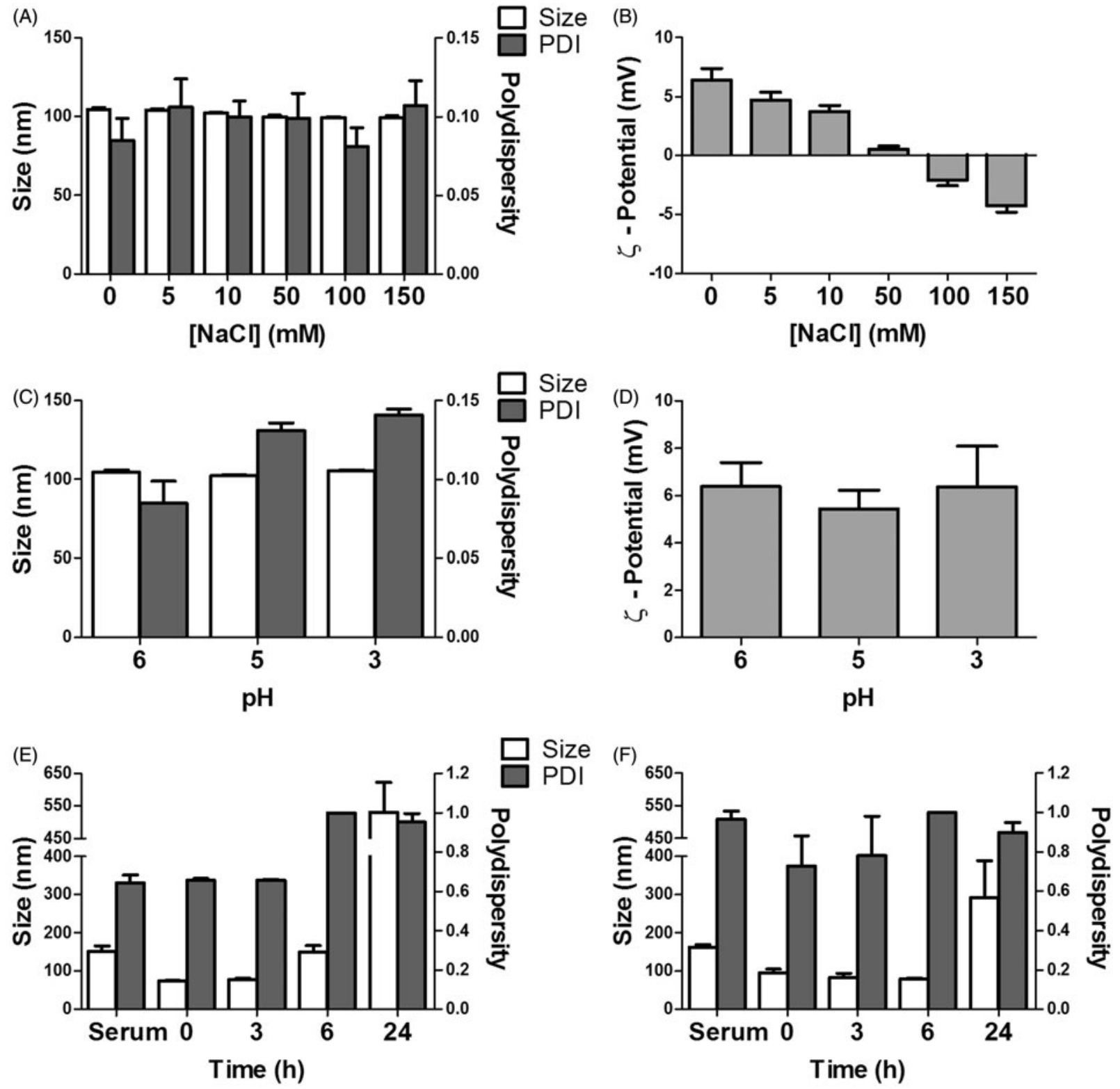

Figure 3. Stability of DODAC:MO:PEG lipoplexes (CR 10) in physiological conditions. Size (nm), PDI values (A) and $\zeta$-potential (mV) (B) of lipoplexes diluted in different $\mathrm{NaCl}$ concentrations; size (nm) and PDI values (C) and $\zeta$-potential (D) of lipoplexes at different pH (6.5 and 3); weighted mean $(W . M$.) diameter and PDI of lipoplexes diluted in 30\% (v/v) (E) and 80\% (v/v) (F) of FBS, after different incubation periods $(0,3,6$ and $4 \mathrm{~h})$. A control of the average W. M. size and PDI of the serum particles (at all studied time points) is shown to attest to its stability along time.

$\left(\chi^{2}=11.480 ; \mathrm{DF}=2 ; p<0.05\right)$ of DODAC:MO:PEG liposomes (from +60 to $+34 \mathrm{mV}$ ) with acidification were obtained (Lopes, 2013).

\section{Lipoplex cytotoxicity}

The metabolic cytotoxic effect of DODAC:MO:PEG lipoplexes (C. R. 10) is shown in Figure 4. For both cell lines, the cell viability decreases as the concentration of lipoplexes increases, reaching very low values $(<10 \%)$ for the highest concentration tested. Interestingly, the MDA-MB-468 cell line was found to be significantly less sensitive to the lipoplexes $(F(12,46)=16.264, p<0.01$, nested ANOVA), with around $75 \%$ viable cells after incubation with $25 \mu \mathrm{g} / \mathrm{mL}$ lipoplexes for $72 \mathrm{~h}$, while for L-929 less than $20 \%$ of the cells were still metabolically active.

\section{Specific cellular uptake of lipoplexes by FR overexpressing cells}

DODAC:MO:PEG lipoplexes were prepared with $0 \%$ or $1 \%$ PEG-Fol to specifically target $\mathrm{FR} \alpha$ overexpressing cells. To confirm this specificity, DODAC:MO:PEG and DODAC:MO:PEG-Fol lipoplexes were tested in MDA-MB468 and MDA-MB-435 cells. These cell lines were previously confirmed to be $\mathrm{FR}^{+}$(MDA-MB-468) and $\mathrm{FR} \alpha^{-}$(MDAMB-435) (data not shown).

To determine the amount of lipoplexes taken up by MDAMB-468 and MDA-MB-435 cells, calibration curves of the fluorescence emission spectrum area in function of the lipid concentration of all systems were constructed, to account for the eventual differences in fluorescence (Lopes, 2013). The fluorescence emission spectrum area was used instead of the 


\section{L-929}
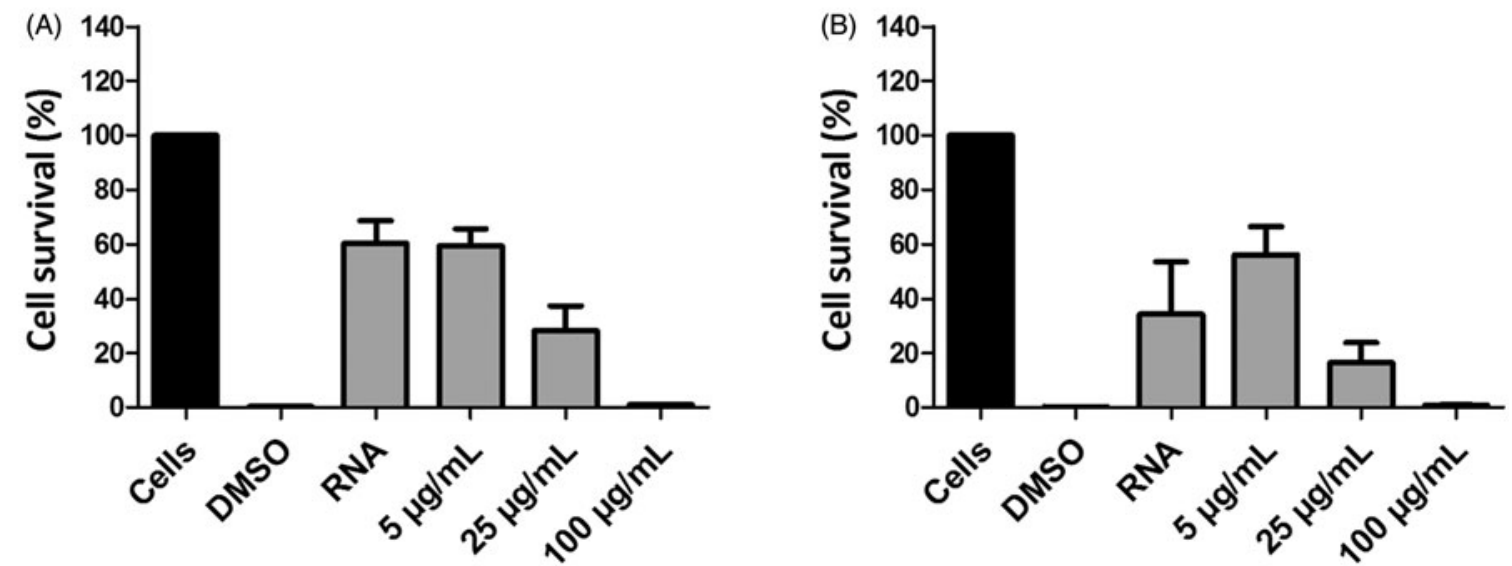

MDA-MB-468

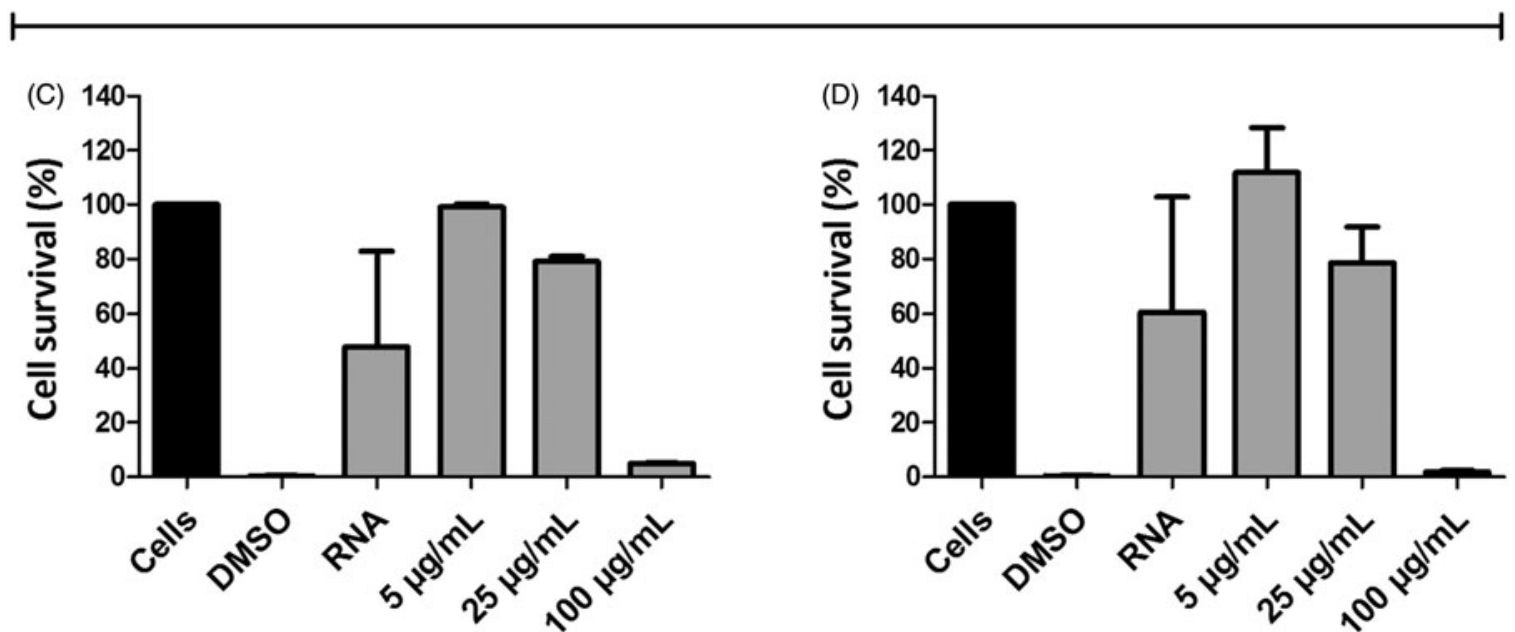

Figure 4. In vitro evaluation of the metabolic cytotoxicity induced by DODAC:MO:PEG lipoplexes on L-929 (A and B) and MDA-MB-468 (C and D) cell lines. DODAC:MO:PEG lipoplexes were incubated at 5, 25 and $100 \mu \mathrm{g} / \mathrm{mL}$ lipid concentration, for 48 (A and C) and $72 \mathrm{~h}$ (B and D). Cell viability was determined by the MTT assay. Cell culture medium, 30\% (v:v) DMSO and RNA were used as controls.

maximum fluoresce emission, or the fluorescence value at the emission wavelength of the rhodamine B DHPE $(580 \mathrm{~nm})$, to avoid issues in signal strength and noise fluctuation.

The calibration curves for liposomes and lipoplexes, of both systems, were found to be very similar. Also, the systems comprising PEG-Fol were less fluorescent than those only with PEG. Finally, the calibration curves of liposomes with PEG and PEG-Fol were chosen to estimate the amount of lipoplexes taken up by the cells, since they have better coefficients of determination.

Figure 5 shows the results of the cellular uptake by MDAMB-468 and MDA-MB-435 cells of DODAC:MO:PEG and DODAC:MO:PEG-Fol lipoplexes, after a 6-h incubation period.

From the results of the cellular uptake experiments, presented as the mean of the two independent assays (Figure 5), it is possible to infer that, for both cell lines and lipid concentrations, the systems with PEG-Fol are more internalized by cells than those lacking folate $(F(4,24)=5.683, p<0.05$, nested ANOVA). Importantly, the vesicles with PEG-Fol are more intensively uptaken by MDA-MB-468 cells $\left(\mathrm{FR} \alpha^{+}\right)$than for the MDA-MB-435
$\left(\mathrm{FR} \alpha^{-}\right)$, which corroborates the effectiveness of our targeting approach in promoting internalization by $\mathrm{FR} \alpha$ expressing cancer cells.

The increase in lipid concentration $(25 \mu \mathrm{g} / \mathrm{mL}$ versus $40 \mu \mathrm{g} / \mathrm{mL}$ ) did not result in an increased uptake of the lipoplexes. Actually, while there is no significant alteration in the percentage of DODAC:MO:PEG lipoplexes taken up by both cell lines (around 15\% in Figure 5A and B), the percentage of PEG-Fol lipoplexes internalized by $\mathrm{FR} \alpha^{+}$and $\mathrm{FR} \alpha^{-}$cells decreases when comparing the 25 and $40 \mu \mathrm{g} / \mathrm{mL}$ concentrations (Figure 5A and B).

\section{Discussion}

We have previously developed and characterized a cationic liposomal formulation, composed by DODAC or DODAB and MO, for nucleic acid delivery (Oliveira et al., 2014; Silva et al., 2011, 2014a,b). Good transfection efficiencies with low toxicities were obtained in those previous studies, suggesting these formulations as promising nanocarriers for several therapeutic applications. With the current study we aimed to direct DODAC:MO (2:1) formulation for specific epithelial 

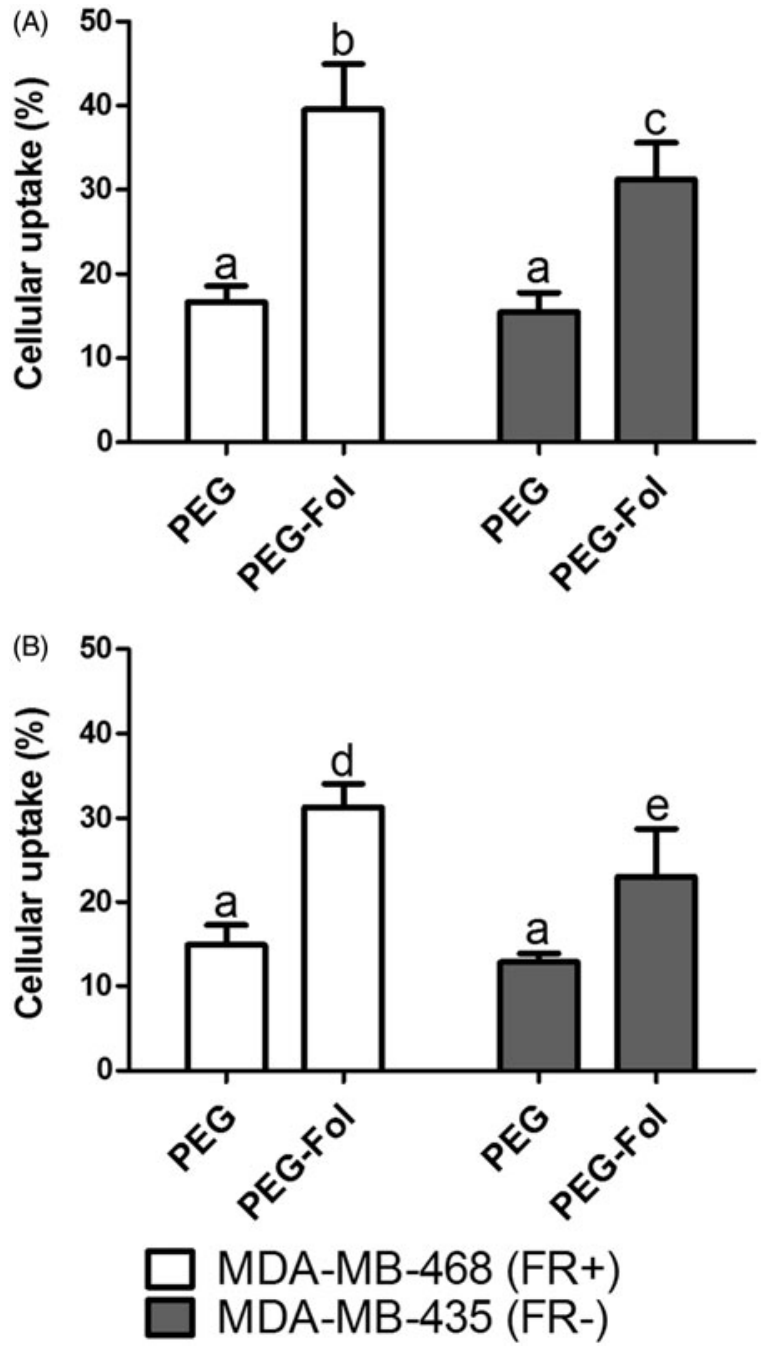

Figure 5. Percentage of cellular uptake of lipoplexes with and without PEG-Fol by MDA-MB-468 and MDA-MB-435 cell lines at lipid concentrations of $25 \mu \mathrm{g} / \mathrm{mL}$ (A) and $40 \mu \mathrm{g} / \mathrm{mL}$ (B) after $6 \mathrm{~h}$ of incubation. Different letters above error bars represent significant statistical differences among the systems.

cancer cell targeting, by taking advantage of the folate receptor overexpression by the target cells. DODAC:MO lipoplexes were stabilized with a PEG-derived lipid, and their physico-chemical characteristics, stability in physiological mimicking conditions, cytotoxic effects and uptake by $\mathrm{FR} \alpha$ overexpressing cells were determined.

PEGylation of cationic liposomes is well described as a strategy to avoid recognition by the immunological system and increase the nanocarriers life-time in the bloodstream (Andresen et al., 2005; Gabizon et al., 2003; Torchilin, 2005). Nevertheless, the ability to achieve these characteristics without compromising the efficiency of the nanocarriers is strongly dependent on the PEG percentage at their surface (Hyvönen et al., 2004; Peeters et al., 2007). Optimization of the PEG percentage on the liposomal formulation was made considering the effect of the polymer on the mean size, surface charge and cytotoxicity of DODAC:MO nanocarriers. We opted not to use percentages of PEG higher than 5\%, since it has been suggested that the flexibility of the polymer allows for the formation of a protective layer even with a small amount of PEG molecules at the surface of the particles (Torchilin, 2005).
A small and uniform mean size distribution was obtained for all liposomes prepared in this study, although the presence of PEG-derived lipids slightly decreased their mean diameter and surface charge (Figure 1). These results are a consequence of the inclusion of the PEG lipid conjugate in the formulation. High amounts of PEG may increase the repulsions between the lipid head groups (Garbuzenko et al., 2005), which leads to an increase in the curvature of the vesicular surface, reducing the lateral tension of the polymer layers. As a result, lipids become more tightly packed and liposomes smaller. At the same time, the large headgroup of PEG lipids mask some positive charges of DODAC, and contribute with negative charges to the $\zeta$-potential of liposomes, decreasing its superficial charge density.

It is known that the presence of PEG does not only affect the physico-chemical characteristics of liposomes, but it also influences the cellular response to the nanocarriers (GomesDa-Silva et al., 2012; Hyvönen et al., 2004). The cytotoxicity induced by the liposomes was found to be concentration dependent, as previously reported (Oliveira et al., 2014; Silva et al., 2012), but PEGylation increased the biocompatibility of liposomes in a dose-dependent manner. This effect of PEGylation was reported earlier for other lipid-based nanoparticles (Kim et al., 2010), and can be explained by the decrease in liposomes positive charge promoted by the PEG-derived lipids (positive charge is associated with high toxicities (Safinya et al., 2011)). Considering the adequate characteristics for systemic administration and the better biocompatibility profile of liposomes with $5 \%$ of PEG, as well as taking into account previous reports by other authors (Ross \& Hui, 1999; Torchilin, 2005), DODAC:MO:PEG liposomes were selected for further experiments, namely evaluation of RNA complexation, lipoplexes stability, cell toxicity and internalization by target cells.

The presence of 5\% PEG at the surface of DODAC:MO liposomes was also found to influence RNA complexation dynamics (Figure 2). At CR below 4, DODAC:MO lipoplexes exhibit high mean diameters and PDI. This may be explained by the prevalence of metastable agglomerates of liposomes sustained by electrostatic attractions between the cationic liposomes and the RNA molecules. Above CR 1, the excess of positive charges promoted, through fusion and/or rupture processes, the reorganization of the aggregates and the incorporation of RNA into multilamellar stacks (Maurer et al., 2001). This change in organization behavior decreases the complexes diameter and neutralizes the initial negative charge of the RNA molecules (Figure 2). Oppositely, PEGylation of lipoplexes resulted in a reduction in mean size and polydispersity, when compared with their nonPEGylated counterparts, as the polymer diminished the number of adhesion points between liposomes, without interfering with oligonucleotide binding. Incorporating PEG lipids into the liposome formulation was also shown to prevent structural transformations of lipoplexes, resulting in stable adhesion and complexation (Maurer et al., 2001).

Although the size and $\zeta$-potential measurements (Figure 2A-D) have shown important differences in the RNA complexation dynamics between the two formulations, the studies with the fluorescent RNA intercalating probe RiboGreen (Figure 2E) indicated a much more similar 
behavior for both systems. The exception was the higher amount of free RNA observed for the complexes with PEG at CR 0.5 and 1, that can be explained by the binding impediment promoted by the polymer, which in turn makes the complexes smaller (as seen in Figure 2). Nevertheless, for both types of liposomes, at CR over 6 the amount of detected free RNA was very low.

Good RNA encapsulation is essential when developing a siRNA delivery system for systemic administration, but the behavior of lipoplexes in physiological environment is determinant for their therapeutic success (Gomes-Da-Silva et al., 2012; Hyvönen et al., 2004; Peeters et al., 2007). Some conditions, faced by nanoparticles when systemically administrated, were mimicked in order to study the stability of DODAC:MO:PEG lipoplexes, namely high-salt concentrations and interaction with serum. Lipoplexes incubated in solutions of increasing $\mathrm{NaCl}$ concentrations showed good colloidal stability, as their size did not fluctuate over time and the PDI was kept low (Figure 3). A tightly packed onionlike structure, similar to that observed for other systems produced by our research group (Silva et al., 2011, 2012. $2014 a, b)$, with low quantities of water in their midst, would explain why the lipoplexes did not shrink due to water loss, in opposition to what was observed for the parent liposomes (Lopes, 2013). The mean diameter of both types of liposomes decreased due to the presence of $\mathrm{NaCl}$, which is explained by the increase in ionic strength in the vicinity of liposomes that promotes a change in osmotic pressure across their membrane. As the membrane is resistant to ion diffusion, water loss becomes the only possibility for equilibrium restoration (Sabín et al., 2006). The water loss promotes an increasingly tighter packing of liposome membranes, reducing their size until the lipids are so tightly packed that the water outflow stops.

Additional characterization would be necessary to clarify the structure of the prepared lipoplexes, but we base our onion-like structural hypothesis on several biophysical characterization studies, including X-ray scattering, cryo-microscopy, NMR and fluorescence, from our group (Silva et al., 2011, 2012, 2014a,b) and other researchers (Bouxsein et al., 2007; Leal et al., 2010).

The effects observed on the $\zeta$-potential with increasing $\mathrm{NaCl}$ concentration are due to alterations of difference of potential between the stern and the diffuse layers. As the concentration of salt increases, the positive charges in the liposomes attract more anions from the diffuse to the stern layer, and the $\zeta$-potential of lipoplexes and liposomes decreases.

In addition, the effect of exposure to serum on the mean size of liposomes and lipoplexes was evaluated. The fact that serum is, by itself, a particulate medium, makes the evaluation of nanocarriers' stability in serum an intrinsically difficult task. Serum proteins are drawn together by electrostatic attractions (albumin is an example of a serum component with well-known capability of interacting with cationic liposomes (Simões et al., 2000)), forming aggregates that are detected by DLS (Figure 3). Nevertheless, the weighted mean diameter of these aggregates is pretty constant along the time points studied, which allows a comparative analysis of the behavior of DODAC:MO and DODAC:MO:PEG nanocarriers when dispersed in a complex medium such as serum. In broad terms, and similarly to what was observed for liposomes, DODAC:MO:PEG lipoplexes appear to be stable up to $6 \mathrm{~h}$ of incubation in serum. Considering the results of the lipoplexes mean size obtained in increasing salt concentrations and in serum, lipoplexes gave indications of a good colloidal stability for intravenous injection.

Another factor often reported to destabilize lipoplexes is their interaction with cell surfaces during internalization. Usually, cellular uptake of siRNA carriers occurs via endocytosis (Lu et al., 2009), which means that for siRNA to reach the RNAi enzymatic machinery it has to escape from the endosome compartment. Although the precise mechanism of endosomal release by delivery systems is still unclear (Schroeder et al., 2010), it is believed that cationic delivery systems are able to escape endosomes by two main mechanisms of membrane disruption (Tan et al., 2011): due to charge neutralization between anionic lipids in the endosomal membrane and the cationic vectors, which can promote membrane destabilization (Zelphati \& Szoka, 1996); or due to the so-called 'the proton sponge effect'" (Midoux et al., 2009). After the uptake of the delivery system, the endosome acidifies and the vector amine groups, which have a $\mathrm{p} K_{\mathrm{a}}$ typically between 7 and 5 , are protonated. Subsequently, an influx of additional protons, as well as of chloride ions, leads to an osmotic imbalance and water enters the endosome to counter balance the osmotic pressure, eventually causing endosome swelling and rupture (Akinc et al., 2005; Sonawane et al., 2003). Despite some controversy as to what extent endosomal escape affects transfection efficiency (Hoekstra et al., 2007; Lu et al., 2009; Zhou et al., 2007), it is believed that proton influx into the endosome may facilitate siRNA unpacking from some vectors. Therefore, in some cases, endocytosis may facilitate siRNA release from lipoplexes prior to its release into the cytoplasm (Wolff \& Rozema, 2008). In this regard, the interaction of DODAC:MO:PEG lipoplexes with a model proteoglycan (heparin) was studied, in order to evaluate lipoplex stability upon interaction with cell membranes and also with negatively charged molecules. Additionally, the behavior of the lipoplexes after cellular internalization was studied by simulating the acidic conditions in endosomes. Results show that the size and surface charge of the lipoplexes remained stable despite the decrease in $\mathrm{pH}$, although liposomes, with and without PEG, became smaller with the reduction of $\mathrm{pH}$ (Lopes, 2013). This may be explained by water loss from the liposomes lumen, which is not observed for tightly packed onion-like structure of the lipoplexes. Additionally, the acidification could have enhanced the water ionization, attracting the resulting hydroxide ions to the liposomes surface and resulting in the reduction of the $\zeta$-potential.

Since the acidification of the medium was not an apparent factor for lipoplex destabilization, and it has been proposed that the release of nucleic acids from cationic lipid complexes may be facilitated by charge neutralization between carrier and cell membrane (Wolff \& Rozema, 2008; Xu \& Szoka, 1996), the effect of the negative charge on DODAC:MO:PEG lipoplexes stability was studied. Our results show that charge neutralization can only partially promote lipoplex destabilization, with $60 \%$ of RNA remaining in the lipoplexes after 
addition of a strong polyelectrolyte as heparin, probably entrapped inside vesicles that result of lipid reorganization processes.

The cytotoxicity associated with DODAC:MO liposomes was previously evaluated on different human cell lines (Oliveira et al., 2014; Silva et al., 2012). While normal cell membrane integrity and cellular proliferation were not negatively affected by the presence of DODAC:MO liposomes, the metabolic assay showed a decrease in cell viability in a dose-dependent way. A similar trend was observed when the cells were incubated with liposomes and DODAC:MO:PEG lipoplexes, with a dramatic decrease in the cell viability for the higher lipid concentrations tested.

The main goal of this system is to achieve specificity toward the folate receptor. To do so, 1\% PEG was replaced by PEG-Fol, and the DODAC:MO:PEG and DODAC:MO:PEG-Fol lipoplexes cellular uptake was evaluated in a $\mathrm{FR} \alpha^{+}$cell line (MDA-MB-468) and $\mathrm{FR} \alpha^{-}$cell line (MDA-MB-435). Although both cell lines were internalized to a similar extent the system without PEG-Fol, through fusion or endocytosis, the analysis of PEG-Fol vesicles uptake clearly indicated significant specificity toward $\mathrm{FR} \alpha^{+}$cells. The internalization of these systems was significantly higher for the MDA-MB-468 cell line, suggesting that these systems must enter the cells by a different pathway than in MDA-MB-435 cells, very likely by FR $\alpha$-mediated endocytosis. Overall, the results point to a specificity of the PEG-Fol systems for the folate receptor, as confirmed by the statistical analysis (Figure 5).

Interestingly, the incubation of the lipoplexes at higher concentration did not increase the cellular uptake, on the contrary, it has impaired it. In terms of percentage, the uptake is lower when higher lipid concentrations are used. This could be the result of some cytotoxic effect promoted by the higher lipid concentration tested.

In general, these results show that the developed systems are very promising for the specific delivery of therapeutic siRNA into cancer cells, as their sizes would allow accumulation at the tumor sites due to the EPR effect (Gomes-DaSilva et al., 2012), and they were highly effective in RNA complexation, stable in conditions simulating their administration by intravenous injection and selectivity toward FR $\alpha$. However, and despite of some RNA release when lipoplexes were incubated with heparin, we expect that their high stability could, to some extent, impair the delivery of RNA in the cytoplasm. Thus, in future silencing experiments with therapeutic siRNA, we may have to replace the PEG-lipid of the formulation with an exchangeable PEG lipid, such as PEG-Ceramide.

\section{Conclusion}

The characterization of the liposomes DODAC:MO and DODAC:MO with 5\% of PEG has shown that these vesicles are stable in increasing concentrations of salt and serum, for up to $6 \mathrm{~h}$, and also when exposed to different $\mathrm{pH}$. Both DODAC:MO and DODAC:MO:PEG liposomes were highly efficient in RNA complexation at CR 10. These lipoplexes were destabilized when incubated with heparin, which suggests they may be sensitive to the negatively charged components of the endosome membrane, which could lead to some release of the loaded RNA.

As expected, liposomes induced lipid-dependent cytotoxicity, both in L-929 and MDA-MB-468 cell lines, and the inclusion of PEG in the formulation seems to be a successful strategy for achieving better cytocompatibility. The cellular uptake was higher for the PEG-Fol lipoplexes compared with their PEG counterparts, showing some specificity toward the FR $\alpha$ expressed by MDA-MB-468 breast cancer cells.

As the produced systems have thus revealed very interesting features for intravenous administration, RNA complexation effectiveness and specificity toward the chosen targeting ligand, that support their further development for specific delivery of therapeutic siRNA, we intend to better comprehend the structure of the systems, by conducting cryo-TEM studies, to corroborate the observed specificity toward FR $\alpha$, with experiments of flow cytometry and confocal microscopy, and to study their silencing effectiveness by assessing the gene expression, for instance, of the epidermal growth factor receptor, using PCR and western blot protocols.

\section{Declaration of interest}

The authors report no conflicts of interest. The authors alone are responsible for the content and writing of this article.

\section{References}

Akinc A, Thomas M, Klibanov AM, et al. (2005). Exploring polyethylenimine-mediated DNA transfection and the proton sponge hypothesis. J Gene Med 7:657-63.

Andresen TL, Jensen SS, Jørgensen K. (2005). Advanced strategies in liposomal cancer therapy: problems and prospects of active and tumor specific drug release. Prog Lipid Res 44:68-97.

Bouxsein NF, McAllister CS, Ewert KK, et al. (2007). Structure and gene silencing activities of monovalent and pentavalent cationic lipid vectors complexed with siRNA. Biochemistry 46:4785-92.

Dabkowska AP, Barlow DJ, Hughes AV, et al. (2012). The effect of neutral helper lipids on the structure of cationic lipid monolayers. J R Soc Interface 9:548-61.

Dokka S, Toledo D, Shi X, et al. (2000). Oxygen radical-mediated pulmonary toxicity induced by some cationic liposomes. Pharm Res 17:521-5.

Filion MC, Phillips NC. (1997). Toxicity and immunomodulatory activity of liposomal vectors formulated with cationic lipids toward immune effector cells. Biochim Biophys Acta 1329:345-56.

Fire AZ. (2007). Gene silencing by double-stranded RNA (Nobel Lecture). Angew Chem Int Ed Engl 46:6966-84.

Gabizon A, Shmeeda H, Barenholz Y. (2003). Pharmacokinetics of pegylated liposomal doxorubicin: review of animal and human studies. Clin Pharmacokinet 42:419-36.

Garbuzenko O, Barenholz Y, Priev A. (2005). Effect of grafted PEG on liposome size and on compressibility and packing of lipid bilayer. Chem Phys Lipids 135:117-29.

Gomes-Da-Silva LC, Fonseca NA, Moura V, et al. (2012). Lipid-based nanoparticles for siRNA delivery in cancer therapy: paradigms and challenges. Acc Chem Res 45:1163-71.

Hoekstra D, Rejman J, Wasungu L, et al. (2007). Gene delivery by cationic lipids: in and out of an endosome. Biochem Soc Trans 35: $68-71$.

Hyvönen Z, Rönkkö S, Toppinen MR, et al. (2004). Dioleoyl phosphatidylethanolamine and PEG-lipid conjugates modify DNA delivery mediated by 1,4-dihydropyridine amphiphiles. J Control Release 99:177-90.

Immordino ML, Dosio F, Cattel L. (2006). Stealth liposomes: review of the basic science, rationale, and clinical applications, existing and potential. Int J Nanomedicine 1:297-315.

Kalli KR, Oberg AL, Keeney GL, et al. (2008). Folate receptor alpha as a tumor target in epithelial ovarian cancer. Gynecol Oncol 108:619-26. 
Kim HK, Davaa E, Myung CS, et al. (2010). Enhanced siRNA delivery using cationic liposomes with new polyarginine-conjugated PEGlipid. Int J Pharm 392:141-7.

Kwon YJ. (2012). Stimuli-converting siRNA/polymer interactions in determining gene silencing efficiency. Acc Chem Res 45:1077-88.

Leal C, Bouxsein NF, Ewert KK, et al. (2010). Highly efficient gene silencing activity of siRNA embedded in a nanostructured gyroid cubic lipid matrix. J Am Chem Soc 132:16841-7.

Lopes I. (2013). Development of stable lipoplexes DODAC-MO-PEGFOL for delivery of nucleic acids to cells expressing folate receptor. MSc thesis in RepositoriUM of the University of Minho. Available from: http://hdl.handle.net/1822/25568.

Lu JJ, Langer R, Chen J. (2009). A novel mechanism is involved in cationic lipid-mediated functional siRNA delivery. Mol Pharm 6: $763-71$.

Lv H, Zhang S, Wang B, et al. (2006). Toxicity of cationic lipids and cationic polymers in gene delivery. J Control Release 114:100-9.

Maeda H. (2001). The enhanced permeability and retention (EPR) effect in tumor vasculature: the key role of tumor-selective macromolecular drug targeting. Adv Enzyme Regul 41:189-207.

Maurer N, Wong KF, Stark H, et al. (2001). Spontaneous entrapment of polynucleotides upon electrostatic interaction with ethanol-destabilized cationic liposomes. Biophys J 80:2310-26.

Midoux P, Pichon C, Yaouanc JJ, et al. (2009). Chemical vectors for gene delivery: a current review on polymers, peptides and lipids containing histidine or imidazole as nucleic acids carriers. Br J Pharmacol 157: 166-78.

Napoli C, Lemieux C, Jorgensen R. (1990). Introduction of a chimeric chalcone synthase gene into petunia results in reversible co-suppression of homologous genes in trans. Plant Cell 2:279-89.

Obata Y, Tajima S, Takeoka S. (2010). Evaluation of pH-responsive liposomes containing amino acid-based zwitterionic lipids for improving intracellular drug delivery in vitro and in vivo. J Control Release 142:267-76.

Oliveira ACN, Martens TF, Raemdonck K, et al. (2014). Dioctadecyldimethylammonium:monoolein nanocarriers for efficient in vitro gene silencing. ACS Appl Mater Interfaces 6:6977-89.

Ozpolat B, Sood AK, Lopez-Berestein G. (2010). Nanomedicine based approaches for the delivery of siRNA in cancer. J Intern Med 267: 44-53.

Peeters L, Sanders NN, Jones A, et al. (2007). Post-pegylated lipoplexes are promising vehicles for gene delivery in RPE cells. J Control Release 121:208-17.

Ross PC, Hui SW. (1999). Polyethylene glycol enhances lipoplex-cell association and lipofection. Biochim Biophys Acta 1421:273-83.

Sabín J, Prieto G, Ruso JM, et al. (2006). Size and stability of liposomes: a possible role of hydration and osmotic forces. Eur Phys J E 20: $401-8$.
Safinya CR, Ewert KK, Leal C. (2011). Cationic liposome-nucleic acid complexes: liquid crystal phases with applications in gene therapy. Liq Cryst 38:1715-23.

Schroeder A, Levins CG, Cortez C, et al. (2010). Lipid-based nanotherapeutics for siRNA delivery. J Intern Med 267:9-21.

Silva JPN, Oliveira ACN, Casal MPPA, et al. (2011). DODAB:monoolein-based lipoplexes as non-viral vectors for transfection of mammalian cells. Biochim Biophys Acta 1808: 2440-9.

Silva JPN, Oliveira ACN, Gomes AC, et al. (2012). Development of DODAB-MO liposomes for gene delivery. In: Gowder S, ed. Cell interaction. Rijeka (Croatia): InTech, Chapter 10, 245-72.

Silva JPN, Oliveira ACN, Lúcio M, et al. (2014a). Tunable pDNA/ DODAB:MO lipoplexes: the effect of incubation temperature on pDNA/DODAB:MO lipoplexes structure and transfection efficiency. Colloids Surf B 121:371-79.

Silva JPN, Oliveira IMSC, Oliveira ACN, et al. (2014b). Structural dynamics and physicochemical properties of pDNA/ DODAB:MO lipoplexes: effect of $\mathrm{pH}$ and anionic lipids in inverted non-lamellar phases versus lamellar phases. Biochim Biophys Acta 1838:2555-67.

Simões S, Slepushkin V, Pires P, et al. (2000). Human serum albumin enhances DNA transfection by lipoplexes and confers resistance to inhibition by serum. Biochim Biophys Acta 1463:459-69.

Sonawane ND, Szoka FC, Verkman AS. (2003). Chloride accumulation and swelling in endosomes enhances DNA transfer by polyamineDNA polyplexes. J Biol Chem 278:44826-31.

Tan SJ, Kiatwuthinon P, Roh YH, et al. (2011). Engineering nanocarriers for siRNA delivery. Small 7:841-56.

Torchilin VP. (2005). Recent advances with liposomes as pharmaceutical carriers. Nat Rev Drug Discov 4:145-60.

Tros de Ilarduya C, Sun Y, Düzgüneş N. (2010). Gene delivery by lipoplexes and polyplexes. Eur J Pharm Sci 40:159-70.

Wolff JA, Rozema DB. (2008). Breaking the bonds: non-viral vectors become chemically dynamic. Mol Ther 16:8-15.

Xu Y, Szoka FCJ. (1996). Mechanism of DNA release from cationic liposome/DNA complexes used in cell transfection. Biochemistry 2960:5616-23.

Yang ST, Zaitseva E, Chernomordik LV, et al. (2010). Cell-penetrating peptide induces leaky fusion of liposomes containing late endosomespecific anionic lipid. Biophys J 99:2525-33.

Zelphati O, Szoka FC. (1996). Mechanism of oligonucleotide release from cationic liposomes. Proc Natl Acad Sci USA 93: 11493-8.

Zhou J, Yockman JW, Kim SW, et al. (2007). Intracellular kinetics of non-viral gene delivery using polyethylenimine carriers. Pharm Res 24:1079-87. 